\title{
Indicadores Clínicos em Psicoterapia com Mulheres Vítimas de Abuso Sexual
}

\author{
Clinical indicators in psychotherapy with \\ women who were victims of sexual abuse \\ Indicadores clínicos en psicoterapia \\ con mujeres víctimas de abuso sexual
}
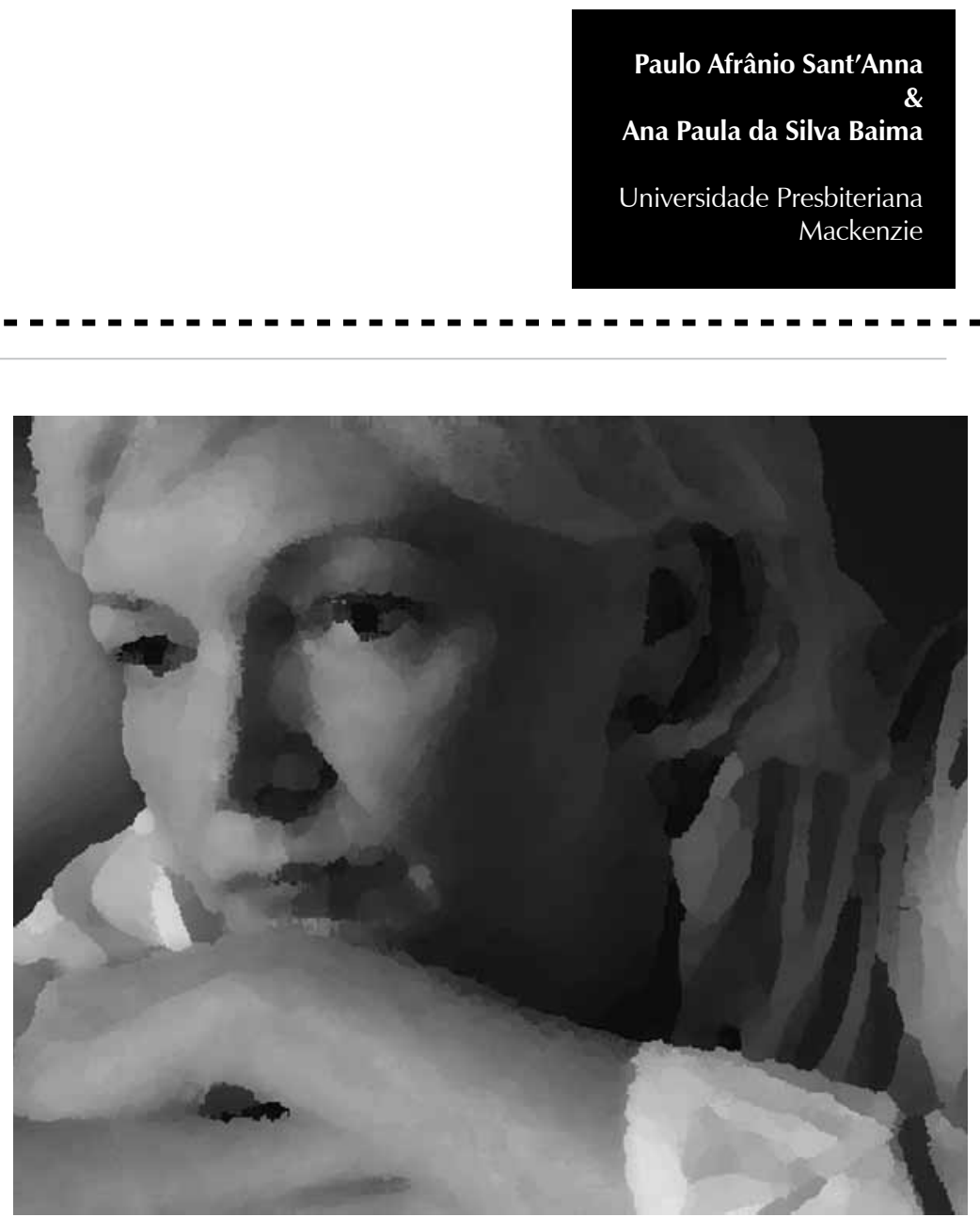
Resumo: O artigo trata das repercussões, a longo prazo, do abuso sexual e busca analisar queixas e sintomas apresentados em psicoterapia por mulheres adultas que foram vítimas de agressões sexuais durante a infância e a adolescência e sua relação com a literatura especializada. $O$ trabalho verifica aspectos do atendimento psicoterápico, identificando o momento do relato do abuso, a condução do tratamento e os seus benefícios, com a utilização do método retrospectivo documental em uma amostra aleatória de 90 prontuários de mulheres na faixa etária entre 20 e 40 anos que foram atendidas em psicoterapia breve, das quais 10\% apresentavam histórico de abuso sexual. Um roteiro de análise ofereceu indicadores sobre a situação de abuso, a situação clínica e o processo psicoterápico. Observou-se sintomatologia que persiste até a vida adulta e que dificulta a adaptação social e afetiva das vítimas. Os resultados reforçam a necessidade de uma compreensão mais profunda sobre a prevenção e a profilaxia com vítimas de abuso sexual.

Palavras-chave: Abuso sexual. Mulher. Psicoterapia. Clínica-escola.

Abstract: This article discusses the repercussions of sexual abuse in the long run and analyzes symptoms and complaints presented in psychotherapy by adult women who were victims during childhood and adolescence and its relation to the specialized literature. It verifies psychotherapeutics issues: the moment when the abuse is reported, the treatment conduction and the benefits of psychotherapy. A retrospective research of documental character was carried out in a random sample of 90 clinical records of women between 20 and 40 years old assisted in brief psychotherapy, of which $10 \%$ had suffered sexual abuse. A list of questions offered analyses indicators about the abuse situation, the clinical situation and the psychotherapeutic process. It was observed that the symptoms persist until adult life, what hinders the victims' social and affective adaptation. The results reinforce the need of a deeper understanding of the psychotherapeutic service offered to the victims of sexual abuse.

Key words: Sexual abuse. Woman. Psychotherapy. Clinic school.

Resumen: El artículo trata de las repercusiones, a largo plazo, del abuso sexual y búsqueda analizar quejas y síntomas presentados en psicoterapia por mujeres adultas que fueron víctimas de agresiones sexuales durante la infancia y la adolescencia y su relación con la literatura especializada. El trabajo verifica aspectos del servicio psicoterápico, identificando el momento del relato del abuso, la conducción del tratamiento y sus beneficios, con la utilización del método retrospectivo documental en una muestra aleatoria de 90 fichas de mujeres en la banda de edades entre 20 y 40 años que fueron atendidas en psicoterapia breve, de las cuales $10 \%$ presentaban histórico de abuso sexual. Un guión de análisis ofreció indicadores sobre la situación de abuso, la situación clínica y el proceso psicoterápico. Se observó sintomatología que persiste hasta la vida adulta y que dificulta la adaptación social y afectiva de las víctimas. Los resultados refuerzan la necesidad de una comprensión más profunda sobre la prevención y la profilaxis con víctimas de abuso sexual.

Palabras-clave: Abuso sexual. Mujer. Psicoterapia. Clínica-escuela.

Define-se o abuso sexual como uma situação na qual a criança ou o adolescente é usado para a gratificação sexual de um adulto, ou mesmo de um adolescente mais velho, baseado em uma relação de poder que pode incluir desde carícias, manipulação da genitália, mama ou ânus até o ato sexual, com ou sem penetração, com ou sem violência (Azevedo, 2001). Embora essa seja uma das formas mais antigas e nocivas de violência, os estudos realizados nos últimos 40 anos pouco têm contribuído no sentido de prevenir e amenizar suas conseqüências (Aded, Dalcin, Moraes, \& Cavalcanti, 2006).
Os dados sobre a incidência de violência sexual na população em geral não são uniformes. Segundo Pfeiffer e Salvagni (2005), é impossível determinar a real prevalência de abuso devido à subnotificação dos casos. A OMS estima, a partir de estudos realizados em várias partes do mundo, que de $7 \%$ a $36 \%$ das meninas e $3 \%$ a $29 \%$ dos meninos sofreram abuso sexual. Jacobsen e Richardson (1987, citado por Maia, 2001) afirmam que "os valores de prevalência que se encontram na literatura apontam um número que oscila entre os 12 e os 38\% em amostras de mulheres na comunidade, e entre 22 e $48 \%$ nas mulheres utentes de serviços psiquiátricos" (p. 347). 
Azevedo e Guerra (1988) classificam a vitimização sexual em três grupos: os que não envolvem contato físico, os que envolvem contato físico e os que envolvem violência. Dentre os que não envolvem o contato físico, pode-se citar: o abuso verbal (telefonemas obscenos), o exibicionismo (exibição do corpo ou parte deste para a criança) e o voyeurismo (observação da nudez total ou parcial da criança). Em relação aos atos que envolvem contato físico, estes incluem: o passar a mão, o coito, o contato oral-genital e o uso sexual do ânus. Quanto ao grupo dos atos que envolvem violência, fazem parte deste o estupro e outras formas violentas de abuso sexual.

Cohen (1993), Azevedo e Guerra (1988) e Amazarray e Koller (1998) dividem o abuso sexual em intrafamiliar e extrafamiliar. $\mathrm{O}$ primeiro, também conhecido como incesto, acontece dentro do núcleo familiar, e está no limite entre dois sentimentos contraditórios: o desejo e o temor (Matias, 2006). O agressor possui relação de parentesco com a vítima e tem sobre esta poder, seja do ponto de vista hierárquico (pai, mãe, tio, padrasto) ou do ponto de vista afetivo (primos e irmãos). Já o abuso sexual extrafamiliar ocorre fora do âmbito familiar e pode ser cometido tanto por conhecidos (vizinhos) como por pessoas desconhecidas.

Meichembaum (1994), Alberto (2002) e Cohen e Gobbetti (2004) salientam que cada caso de abuso sexual possui características singulares, e isso influencia os efeitos gerados na vida presente e futura das vítimas.
Muñoz, 2007), a ansiedade, a ideação suicida, a impulsividade, a delinqüência, a hiperatividade, a dificuldade nos relacionamentos, o uso abusivo de substâncias químicas, lícitas e ilícitas (Teicher, 2000), a auto-estima rebaixada, o déficit de percepção (Matias, 2006), as disfunções sexuais e os transtornos de comportamento, sendo a violência mais freqüente em homens e a autodestrutividade, em mulheres (Echeburúa \& Corral, 2006), saúde geral mais frágil, fadiga crônica, doenças gastroentestinais, gravidez indesejada e, devido aos comportamentos sexuais prosmíscuos e de risco, maior exposição às doenças sexualmente transmissíveis (RiveraRivera, Allen, Chávez-Ayala, Ávila-Burgos, 2006).

Alguns fatores determinam o impacto do abuso sexual: a idade da vítima e a diferença de idade entre a vítima e o agressor - quanto maior a diferença, mais graves são as conseqüências; o grau de parentesco e proximidade entre o agressor e a vítima - quanto mais próximo, maior o impacto; a topografia do ato sexual - carícias, exibição de órgãos sexuais, penetração etc; o grau de violência e ameaças; a duração do abuso e a freqüência dos atos; as características do contexto familiar e o suporte dado à vítima antes, durante e depois da revelação (Meichembaum,1994).

Meichembaum (1994), Alberto (2002) e Cohen e Gobbetti (2004) salientam que cada caso de abuso sexual possui características singulares, e isso influencia os efeitos gerados na vida presente e futura das vítimas.

Apesar da complexidade da situação e da quantidade de variáveis envolvidas, KendallTackett, Williams e Finkelhor (1993) ressaltam que sintomas como ansiedade, medo, ocorrência de pesadelos, depressão, retraimento social, queixas somáticas e comportamentos agressivos 
são bastante freqüentes em crianças que sofreram abuso. De acordo com esses autores, existe a tendência de os sintomas do abuso sexual infantil desaparecerem com o tempo (12 a 18 meses após o incidente abusivo). Assim, nem todos os sintomas persistem até a vida adulta. No entanto, há uma parcela considerável de casos (entre 10 a 24\% destes) cuja sintomatologia piora com o tempo.

Diante da complexidade e da gravidade desse quadro, faz-se necessário aprofundar a compreensão sobre o abuso sexual na infância e o seu impacto na vida adulta das vítimas, de modo a contribuir para a construção de modalidades de atendimento mais eficientes. Nesse sentido, além de novos estudos, devem ser criadas e mantidas equipes multidisciplinares capacitadas para lidar com os diversos aspectos que envolvem essa questão (Aded et al., 2006). Em relação à equipe de saúde mental, Vitriol et al. (2007) destacam a importância de maior preparo para abordar ativamente os traumas sexuais e entender as suas conseqüências.

No campo da Psicologia, observa-se um baixo número de referências sobre os aspectos da prática psicoterápica e das dificuldades que o psicoterapeuta enfrenta no tratamento das vítimas de abuso (Numhauser \& Soto, 2006). Segundo Habigzang, Hatzenberger, Corte, Stroeher e Koller (2008), no Brasil, quase não há estudos controlados para avaliar os resultados de tratamentos, o que inviabiliza a padronização de procedimentos.

Nesse sentido, este estudo tem como objetivo identificar e descrever aspectos clínicos em processos psicoterápicos de mulheres com histórico de abuso sexual na infância, apresentando dados sobre o ato abusivo, sobre os sintomas observados na vida adulta e sobre o desenvolvimento do processo psicoterápico.
Tendo em vista que os atendimentos estudados foram realizados em uma clínica-escola de Psicologia, espera-se também contribuir com reflexões sobre a relevância desse tema no processo de formação do futuro terapeuta.

\section{Método}

O método empregado na pesquisa foi de natureza retrospectiva documental. Utilizouse uma amostra inicial de 90 prontuários de mulheres na faixa etária de 20 a 40 anos, sem restrição quanto à escolaridade e classe social, que foram atendidas em psicoterapia breve de orientação psicanalítica, analítica ou fenomenológica na clínica-escola de Psicologia de uma universidade na cidade de São Paulo.

A análise dos prontuários apoiou-se num roteiro estruturado para a identificação e a caracterização das mulheres vítimas de abuso sexual infantil. Esse continha 34 questões, sendo 10 de caracterização dos sujeitos de pesquisa (1 a 10), 11 a respeito da situação de abuso (11 a 22), 4 referentes ao agressor (23 a 26) e 8 abordando a situação clínica atual da vítima e o processo psicoterápico (27 a 34).

Nos prontuários, primeiramente foram analisados as entrevistas de triagem e os relatórios finais, nos quais se identificou a queixa inicial, a história clínica e a síntese psicológica. A partir desses dados, buscou-se responder às questões referentes à caracterização (1 a 10). Os casos que responderam positivamente à questão 10, relativa à presença de abuso sexual na infância, foram selecionados e constituíram um recorte específico da amostra - mulheres com histórico de abuso sexual $(n=9)$. Nos prontuários desse grupo, realizou-se a leitura das sessões de psicoterapia buscando responder às outras questões do roteiro (11 a 34). 
O projeto foi submetido e aprovado pelo Comitê de Ética da Universidade Presbiteriana Mackenzie (protocolo CEP/UPM no 634/06/04).

\section{Discussão dos resultados}

Tabela 1. Indicadores gerais da amostra.

\begin{tabular}{|c|c|c|}
\hline Idade no momento da triagem & FA & FR \\
\hline 20 a 25 & 4 & $44,5 \%$ \\
\hline 26 a 30 & 0 & $0 \%$ \\
\hline 31 a 35 & 2 & $22,2 \%$ \\
\hline 36 a 40 & 3 & $33,3 \%$ \\
\hline Total & 9 & $100 \%$ \\
\hline Motivo da primeira consulta & FA & FR \\
\hline Encaminhamento do psiquiatra & 4 & $44,5 \%$ \\
\hline Outro encaminhamento & 1 & $11,1 \%$ \\
\hline Autodeterminação & 4 & $44,5 \%$ \\
\hline Total & 9 & $100 \%$ \\
\hline Idade que sofreu abuso sexual & FA & FR \\
\hline 5 a 10 & 4 & $44,5 \%$ \\
\hline 11 a 15 & 3 & $33,3 \%$ \\
\hline 16 a 18 & 1 & $11,1 \%$ \\
\hline Sem dados & 1 & $11,1 \%$ \\
\hline Total & 9 & $100 \%$ \\
\hline Tipo de Abuso & FA & FR \\
\hline Conversas obscenas & 1 & $5,9 \%$ \\
\hline Excitação sexual do adulto frente & 2 & $11,7 \%$ \\
\hline \multicolumn{3}{|l|}{ à nudez total ou parcial da vítima } \\
\hline Relações sexuais impostas & 2 & $11,7 \%$ \\
\hline Masturbação forçada & 6 & $35,3 \%$ \\
\hline Carícia nos órgãos genitais & 6 & $35,3 \%$ \\
\hline Total & 17 & $99,9 \%$ \\
\hline Presença de violência & FA & FR \\
\hline Não & 9 & $100 \%$ \\
\hline Sim & 0 & $0 \%$ \\
\hline Total & 9 & $100 \%$ \\
\hline Presença de violência & FA & FR \\
\hline Não & 3 & $33,3 \%$ \\
\hline Sim & 2 & $22,2 \%$ \\
\hline Sem dados & 4 & $44,5 \%$ \\
\hline Total & 9 & $100 \%$ \\
\hline & & ontinua) \\
\hline
\end{tabular}


Tabela 1. (Continuação)

\begin{tabular}{lll}
\hline Para quem revelou antes da terapia? & FA & FR \\
\hline Ninguém & 7 & $77,7 \%$ \\
Amigo & 1 & $11,1 \%$ \\
Irmã & 1 & $22,2 \%$ \\
Total & 9 & $100 \%$ \\
\hline Alguém soube dos atos ou houve denúncia? & FA & FR \\
\hline Não & 9 & $100 \%$ \\
Sim & 0 & $0 \%$ \\
Total & 9 & $100 \%$ \\
\hline Período de ocorrência dos abusos & FA & FR \\
\hline Único episódio & 3 & $33,3 \%$ \\
Mais de 1 ano & 3 & $33,3 \%$ \\
Sem dados & 3 & $33,3 \%$ \\
Total & 9 & $99,9 \%$ \\
\hline Agressor & FA & FR \\
\hline Pai & 1 & $11,1 \%$ \\
Tio & 3 & $33,3 \%$ \\
Primo & 1 & $11,1 \%$ \\
Irmão & 1 & $11,1 \%$ \\
Vizinho & 1 & $11,1 \%$ \\
Outros & 2 & $22,2 \%$ \\
Total & 9 & $99,9 \%$ \\
\hline Sintomas na época do abuso & FA & FR \\
\hline Medo & 3 & $27,3 \%$ \\
Culpa & 2 & $18,2 \%$ \\
Sem dados & $64,5 \%$ \\
\hline Total & 11 & $100 \%$ \\
\hline & & \\
\hline
\end{tabular}

Embora a amostra final tenha sido de um tamanho reduzido $(n=9)$, os dados obtidos na análise dos prontuários permitiram a visualização de aspectos significativos para a proposta deste estudo. Verificou-se que $10 \%$ das mulheres atendidas na clínica psicológica que compuseram a amostra inicial $(n=90)$ relatam ter sofrido algum tipo de abuso sexual durante a infância e/ou adolescência. A prevalência de $10 \%$ corresponde ao descrito na literatura para a população geral, entre $7 \%$ e $36 \%$. Essa prevalência é bastante significativa, tendo em vista alta letalidade do abuso para a vida psíquica das vítimas e sua repercussão nas esferas biopsicossocial.

$\mathrm{Na}$ amostra final, 44,5 \% das mulheres procuraram auxílio psicológico em função de encaminhamento psiquiátrico. Esse dado contribui para a afirmação de que o abuso sexual infantil é um fator de risco para distúrbios psiquiátricos na vida adulta (Aded et al., 2006; Echeburúa \& Corral, 2006; Meichembaum,1994). Nesse caso, a gênese de sintomas responsáveis por 
limitações em diversas áreas da vida das vítimas pode estar relacionada com esse trauma. No estudo de Vitriol et al. (2007), destaca-se a importância de explorar a hipótese de abuso sexual em quadros de depressão severa ou crônica.

Em 44,5 \% dos casos da amostra, o abuso sexual ocorreu entre 5 e 10 anos de idade, período inicial de estruturação da personalidade e de inserção no meio social, o que aumenta a possibilidade de distúrbios psíquicos estruturais com efeitos nocivos na vida adulta. Em 33,3\% dos casos, o abuso ocorreu na primeira fase da adolescência, período em que, a partir do surgimento das características sexuais secundárias, o desenvolvimento da sexualidade se acelera e a identidade começa a ganhar contornos mais definidos. Nesse caso, são maiores as possibilidades de perturbações na esfera sexual e identitária.

Em relação aos tipos de abuso sexual relatados, o ato sexual com penetração ocorreu em $11,7 \%$ dos casos, sendo que os tipos de abusos relatados com mais freqüência são masturbação forçada (35,3\%), carícias nos órgãos genitais (35,3\%) e excitação sexual do adulto frente à nudez total ou parcial da vítima $(17,6 \%)$.

Observa-se, na amostra estudada, a ausência de referências sobre agressões físicas durante os abusos e um índice relativamente baixo de ameaças explícitas em relação à vítima $(22,2 \%)$. Entretanto, em 77,7 \% dos casos, as vítimas não contaram ou pediram ajuda para outras pessoas, o que pode indicar submissão a outros tipos de coerção.

A manutenção do segredo sobre a situação abusiva mantém a vítima em uma situação de vulnerabilidade e coerção, pois não permite que ela peça e/ou receba ajuda de outras pessoas, fato esse que pode estar relacionado à etiologia de transtornos afetivos e adaptativos caracterizados pela ansiedade, insegurança, agressividade e falta de confiança no outro.

Em 66,6\% dos casos, o agressor pertencia à família da vítima (pai, tio, irmão ou primo), o que, somado ao segredo e à ausência de denúncia, corroboram a observação de Aded et al. (2006) e Alberto (2002) de que os casos de abuso sexual infantil ocorrem geralmente dentro do núcleo familiar e dificilmente são divulgados. Esse dado também encontra ressonância em autores como Neumann (2002), Maia (2001), Cohen e Gobbetti (2004), Ferreira (2000), Cohen (1993), Azevedo e Guerra (1989), Amazarray e Koller (1998), que afirmam que os agressores sexuais são, em sua maioria, do sexo masculino e possuem uma relação afetiva com a vítima.

Além da situação de coerção e desamparo, a experiência de abuso é acompanhada de sentimento de culpa e medo, que estão presentes na fase aguda do transtorno de estresse pós-traumático, freqüente em crianças vitimizadas (Ferreira, 2000). Os dados obtidos nos prontuários estudados corroboram essa afirmação, sendo que os únicos sintomas citados como presentes na época das agressões foram culpa (18,2\%) e medo $(27,3 \%)$. 
Tabela 2. Indicadores sobre os sintomas que podem estar relacionados ao abuso sexual na infância.

\begin{tabular}{|c|c|c|}
\hline Sintomas Psíquicos & FA & FR \\
\hline Ansiedade & 6 & $10,9 \%$ \\
\hline Depressão & 5 & $9,1 \%$ \\
\hline Ideação suicida & 4 & $7,3 \%$ \\
\hline Dificuldade de confiar nos outros & 4 & $7,3 \%$ \\
\hline Baixa auto-estima & 4 & $7,3 \%$ \\
\hline Insegurança & 5 & $9,1 \%$ \\
\hline Dificuldade de tomar decisões & 4 & $7,3 \%$ \\
\hline Sentimento de fracasso e incapacidade & 4 & $7,3 \%$ \\
\hline Imaturidade & 2 & $3,6 \%$ \\
\hline Culpa & 9 & $16,3 \%$ \\
\hline Fantasias de liberdade & 3 & $5 \%$ \\
\hline Pensamentos intrusivos & 2 & $3,6 \%$ \\
\hline Perda de memória & 3 & $5,4 \%$ \\
\hline Total & 55 & $99,9 \%$ \\
\hline Sintomas comportamentais & FA & FR \\
\hline Revitimização & 6 & $18,2 \%$ \\
\hline Promiscuidade & 7 & $21,2 \%$ \\
\hline Tentativas de suicídio & 1 & $2,9 \%$ \\
\hline Isolamento e retraimento & 5 & $15,1 \%$ \\
\hline Agressividade & 2 & $6,1 \%$ \\
\hline Comportamentos compulsivos & 4 & $12,1 \%$ \\
\hline Necessidade de controle & 2 & $6,1 \%$ \\
\hline Uso de substâncias químicas & 6 & $18,2 \%$ \\
\hline Total & 33 & $99.9 \%$ \\
\hline Sintomas no âmbito sexual & FA & $\mathbf{F R}$ \\
\hline Não sente prazer no ato sexual & 5 & $27,8 \%$ \\
\hline Sente-se como objeto no ato sexual & 2 & $11,1 \%$ \\
\hline Não tem desejo e evita o ato sexual & 5 & $27,8 \%$ \\
\hline Sente culpa após ato sexual & 3 & $16,6 \%$ \\
\hline Tem relações sexuais com pessoas desconhecidas & 3 & $16,6 \%$ \\
\hline Total & 18 & $99,9 \%$ \\
\hline Sintomas no âmbito interpessoal & FA & FR \\
\hline $\begin{array}{l}\text { Dificuldade de estabelecer } \\
\text { relacionamentos duradouros }\end{array}$ & 5 & $31,25 \%$ \\
\hline Sofre agressões físicas e/ou verbais & 4 & $25 \%$ \\
\hline Dificuldade de superar decepção amorosa & 4 & $25 \%$ \\
\hline $\begin{array}{l}\text { Preocupação excessiva com a } \\
\text { opinião dos outros }\end{array}$ & 3 & $18,75 \%$ \\
\hline Total & 16 & $\begin{array}{c}100 \% \\
\text { ontinua) }\end{array}$ \\
\hline
\end{tabular}


Tabela 2. (Continuação)

\begin{tabular}{lll}
\hline Sintomas orgânicos & FA & FR \\
\hline Perturbação do sono & 1 & $11,1 \%$ \\
Transtornos alimentares & 2 & $22,2 \%$ \\
Outros transtornos somáticos & 6 & $66,6 \%$ \\
Total & 9 & $99,9 \%$ \\
\hline
\end{tabular}

Na mostra estudada, observa-se uma grande variedade de sintomas psíquicos que, segundo a literatura, podem estar relacionados com o abuso sexual. O sentimento de culpa foi citado em todos os casos, seguido da ansiedade, depressão, baixa auto-estima, insegurança e ideações suicidas. Segundo Azevedo e Guerra (1989), todos esses sintomas, freqüentes em mulheres vitimizadas, contribuem para a ocorrência de dificuldades de adaptação afetiva, interpessoal e sexual.

Além desses sintomas, observou-se a presença de sintomas com consideráveis impactos nas esferas biopsicossocial não citados na literatura especializada, como dificuldade de confiar nos outros, fantasias de liberdade, pensamentos intrusivos, perda de memória, sentimento de fracasso e incapacidade, dificuldade de tomar decisões e imaturidade psíquica.

Quanto aos sintomas comportamentais, constatou-se que a promiscuidade, a incapacidade de evitar situações de revitimização e o uso abusivo de substâncias químicas, lícitas e ilícitas, são os mais freqüentes nesses casos. Seis das nove pacientes estudadas afirmam ter sofrido outros abusos sexuais após a primeira vitimização. Isso aponta dificuldades nos relacionamentos interpessoais e sexuais e também evidencia a situação de vulnerabilidade na qual as mulheres vítimas de abuso permanecem. Rivera-Rivera et al. (2006), em um estudo com mulheres mexicanas, verificam uma relação significativa entre experiências de violência física e sexual durante a infância e situações de violência física e sexual com o parceiro na vida adulta.

As dificuldades no relacionamento interpessoal são acompanhadas de perturbações na esfera sexual, que, segundo

Azevedo e Guerra (1989), estão relacionadas ao fato de que o aumento da intimidade pode fazer com que as vítimas revivam as experiências traumáticas de abuso, o que as levaria a evitar relações ou a perder o desejo sexual.
O uso abusivo de substâncias químicas, também presente na literatura (Finkelhor \& Browne, 1986), pode indicar deficiências psicoadaptativas assim como maior grau de vulnerabilidade. Na amostra, aparece com mais freqüência o uso de antidepressivos e estabilizadores de humor do que de álcool e drogas, o que pode estar relacionado à alta incidência de tratamentos psiquiátricos no grupo.

Outros aspectos observados referem-se ao âmbito sexual e interpessoal. Mais da metade das mulheres da amostra $(n=5)$ tem dificuldade de estabelecer relacionamentos duradouros, o que pode estar ligado à dificuldade de confiar nas pessoas, observada como um sintoma bastante freqüente nesse grupo. Destaca-se a dificuldade em superar as decepções amorosas, o que pode ser uma maneira inconsciente de as vítimas se manterem conectadas à situação traumática de abuso. É também significativa a ocorrência de agressões físicas e verbais contra as mesmas, o que sugere que a revitimização acaba ocorrendo também em outras esferas do relacionamento.

As dificuldades no relacionamento interpessoal são acompanhadas de perturbações na esfera sexual, que, segundo Azevedo e Guerra (1989), estão relacionadas ao fato de que o aumento da intimidade pode fazer com que as vítimas revivam as experiências traumáticas de abuso, o que as levaria a evitar 
relações ou a perder o desejo sexual. Embora a falta de desejo e a esquiva em relação ao contato sexual sejam predominantes na amostra, observa-se que todas as mulheres estudadas têm vida sexual ativa e, em grande parte, de natureza promíscua. Esse dado conduz à hipótese de uma tentativa inconsciente de reeditar a situação abusiva.

A ocorrência de sintomas orgânicos foi observada com freqüência significativa na amostra, embora de forma dispersa. Destacam-se, entre eles, os transtornos alimentares, que foram relatados por duas pacientes.

Tabela 3. Indicadores sobre o processo psicoterápico.

\begin{tabular}{|c|c|c|}
\hline Forma de apresentação do abuso na psicoterapia & FA & FR \\
\hline Queixa primária & 0 & $0 \%$ \\
\hline Queixa secundária & 1 & $11 \%$ \\
\hline Conteúdo de sessão & 8 & $89 \%$ \\
\hline Total & 9 & $100 \%$ \\
\hline Etapa da terapia na qual ocorre o relato sobre o abuso & FA & $\mathbf{F R}$ \\
\hline Sessões iniciais & 2 & $22,2 \%$ \\
\hline Fase intermediária & 7 & $77,7 \%$ \\
\hline Total & 9 & $99.9 \%$ \\
\hline $\begin{array}{l}\text { Ocorrências no processo terapêutico } \\
\text { após o relato do abuso }\end{array}$ & FA & FR \\
\hline Atrasos & 2 & $22,2 \%$ \\
\hline Faltas & 2 & $22,2 \%$ \\
\hline Melhora na aliança terapêutica & 5 & $55,5 \%$ \\
\hline Total & 9 & $99,9 \%$ \\
\hline Remissão de sintomas & FA & FR \\
\hline Sim & 7 & $77,7 \%$ \\
\hline Sem dados & 2 & $22,2 \%$ \\
\hline Total & 9 & $99,9 \%$ \\
\hline Finalização do processo terapêutico & FA & $\mathbf{F R}$ \\
\hline Alta & 5 & $55,5 \%$ \\
\hline Encaminhamento para psicoterapia de longa duração & 3 & $33,3 \%$ \\
\hline Desistência & 1 & $11,1 \%$ \\
\hline Total & 9 & $99,5 \%$ \\
\hline Falhas nos registros & FA & $\mathbf{F R}$ \\
\hline Escolaridade & 1 & 6,6 \\
\hline Idade da vítima & 1 & 6,6 \\
\hline Ocorrência de ameaças & 4 & 26,7 \\
\hline Período de ocorrência de abusos & 3 & 20 \\
\hline Sintomas na época do abuso & 6 & 40 \\
\hline Total & 15 & $99,9 \%$ \\
\hline
\end{tabular}


Verificou-se, na amostra, que o abuso não foi apresentado como queixa primária, sendo que, em $89 \%$ dos casos, foi exposto pelas pacientes como um acontecimento entre outros de sua história de vida. Esse dado, somado ao fato de que grande parte das vítimas ainda não havia contado sobre o abuso a nenhuma pessoa antes da terapia, vai de encontro às observações de Alberto (2000) de que a maioria das vítimas de abuso sexual durante a infância ou adolescência somente relata o abuso sofrido na vida adulta quando procura auxílio psicológico em função de outras queixas.

Tendo em vista que, em $77,7 \%$ dos casos da amostra, a paciente só apresentou a questão do abuso para ser trabalhada na fase intermediária do processo psicoterápico, infere-se a necessidade do estabelecimento de um vínculo de confiança com o terapeuta que favoreça a abordagem desse tema.

Após o relato de experiência de abuso sexual, observou-se melhora no vínculo terapêutico em $55,5 \%$ dos casos, em contraponto com sinais de alterações dessa relação (faltas e atrasos após a revelação) em 44\% dos casos. Esses dados sugerem que, apesar de não ser apresentado como queixa inicial, o abuso é um fator de extrema relevância para o processo terapêutico, podendo dificultá-lo ou até inviabilizá-lo.

Em 77,7\% dos casos da amostra, após o processo de psicoterapia breve, ocorreu a diminuição dos sintomas, sendo que 55,5\% dessas pacientes finalizam o atendimento por alta. Esses dados sugerem um impacto positivo da psicoterapia na minimização dos sintomas relacionados ao abuso.
Vitriol et al. (2007) destacam a importância da presença de um confidente que valide a experiência da vítima de abuso sexual. Os autores citam o estudo de Bulik (2002), no qual a equipe de saúde ocupou o lugar do confidente, que ouviu e validou a experiência de abuso. Essa estratégia facilitou a discussão do assunto entre as pacientes atendidas e seus parceiros, o que contribuiu para o rápido alívio dos sintomas e para a diminuição das dificuldades na esfera sexual.

É significativo o fato de que, durante o processo psicoterápico, a maior parte das vítimas não presta informações sobre o período em que os atos ocorreram e sobre o agressor. Esse dado pode indicar que a vivência do abuso, quando não elaborada conscientemente, pode permanecer circunscrita por tabus que dificultam a exploração analítica da mesma.

Nos registros dos atendimentos estudados, observaram-se falhas que tornaram mais difícil o estudo posterior dos mesmos. As mais freqüentes foram: faltas de dados sobre os sintomas na época do abuso, a ocorrência de ameaças e o período de ocorrência de abusos. Esses três aspectos estão diretamente relacionados à situação do abuso, o que leva à hipótese de dificuldades tanto do paciente quanto do estagiário. Para o primeiro, por se tratar se uma situação extremamente ansiogênica, e, para o segundo, pela imaturidade e inabilidade em explorar a situação traumática. Além desses fatores, os aspectos orgânicos aparecem descritos como questões secundárias e de forma pouco detalhada.

A partir dos dados obtidos neste estudo, foi possível verificar uma expressiva correspondência entre os sintomas relatados 
pelas pacientes e os descritos na literatura (Echeburúa \& Corral, 2006; Rivera-Rivera et al., 2006). Os dados sugerem que esse tipo de violência pode afetar de forma significativa a personalidade das pessoas agredidas, e, como apontado por Amazarray e Koller (1998), pode gerar conseqüências físicas, emocionais, comportamentais e sociais na vida adulta das mesmas.

Na amostra pesquisada, em $100 \%$ dos casos, o abuso sofrido na infância ou adolescência não foi percebido ou compartilhado com outra pessoa, e, em $77,7 \%$ dos casos, na terapia foi a primeira vez em que foi revelado para alguém. Essa situação pode estar relacionada à "síndrome do secretismo", apontada por Furniss (1993) como típica nos casos de abuso sexual, sobretudo os que ocorrem dentro do círculo familiar. O segredo mantido pelas vítimas pode ser considerado um dos fatores responsáveis pela dificuldade encontrada na quantificação desses casos, pois, conforme Neumann (2002) e Aded et

De acordo com Azevedo e Guerra (1989), as dificuldades

de adaptação afetiva, interpessoal e sexual são

sintomas ligados à culpa que as vítimas apresentam por terem mantido segredo durante muito tempo, por sentirem ódio dos agressores ou por terem sentido algum prazer físico nas situações de abuso. al. (2006), a estimativa é que somente uma pequena parcela dos casos de violência sexual contra crianças chega ao conhecimento das autoridades de saúde que trabalham com o problema.

A não revelação do abuso pode contribuir para a proliferação de sintomas. Por não conseguir abordar a questão com outras pessoas, a vítima não recebe atenção e tratamento adequado na época dos episódios abusivos, o que pode mantê-la numa situação de abuso por um longo período e gerar danos psíquicos difíceis de serem revertidos (Universidade de Guadalajara, 1998).

Observou-se, na amostra, a presença de uma sintomatologia característica que dificulta a adaptação social e afetiva das vítimas de abuso, como: sentimento de culpa, baixa auto-estima, ansiedade, ideação suicida, dificuldade em tomar decisões, sentimento de incapacidade e de fracasso, depressão, insegurança e dificuldade de confiar nas pessoas.

Dentre os sintomas psíquicos, destacou-se o sentimento de culpa, citado em todos os casos. Esse sentimento parece estar na base da dinâmica psíquica das vítimas e da estruturação dos demais sintomas. Conforme Cohen (1993), a psicanálise defende a hipótese de que o desejo do incesto é universal e intrínseco ao ser humano. Para Stein (1978), a criança precisa inibir o instinto sexual infantil para que este deixe de ser um impulso predominantemente biológico e passe a ser o impulso do desenvolvimento psicológico. Nos casos em que ocorre o abuso sexual, a criança acredita que não foi capaz de conter esses instintos, e a culpa se torna o sintoma mais significativo. De acordo com Azevedo e Guerra (1989), as dificuldades de adaptação afetiva, interpessoal e sexual são sintomas ligados à culpa que as vítimas apresentam por terem mantido segredo durante muito tempo, por sentirem ódio dos agressores ou por terem sentido algum prazer físico nas situações de abuso.

A mulher vitimizada parece se colocar em situação de risco com mais facilidade, o que, somado a outros comportamentos, como promiscuidade, tentativa de suicídio e ao próprio sentimento de culpa, pode sinalizar uma tentativa de auto-punição. Frente a essa situação, observa-se a necessidade do desenvolvimento de ações preventivas visando a diminuir a possibilidade de que essas mulheres sofram novas formas de abuso (Rivera-Rivera et al., 2006). 


\section{Considerações finais}

A partir deste estudo, evidencia-se a importância de pesquisas sobre as variáveis presentes no tratamento psicoterapêutico oferecido às vítimas de abuso sexual e as suas implicações na formação de terapeutas, constatação compartilhada por vários autores (Aded et al., 2006; Habigzang et al., 2008; Numhauser \& Soto, 2006; Vitriol, 2005; Vitriol. et al., 2007).

No caso da clínica-escola onde foi realizada a coleta de dados, certas dificuldades foram observadas, visto que diversas informações relevantes para a exploração desse quadro clínico não foram devidamente investigadas. Tal fato pode estar ligado à escassa experiência profissional dos terapeutas de uma clínicaescola, que, na condição de estudantes, podem apresentar mais dificuldades em lidar com a complexidade desses casos, ou ao baixo nível de subsídios teóricos e técnicos recebidos em sua formação. Portanto, junto à ampliação do conhecimento sobre o tema, é necessário melhor preparo profissional, iniciado na graduação, que favoreça a identificação e o tratamento dos sintomas psíquicos relacionados ao abuso sexual.

Aded et al. (2006), mediante revisão da literatura, discutem a baixa qualidade dos registros em estudos retrospectivos documentais. Os autores trabalham com a hipótese de que o despreparo dos profissionais da saúde para explorar e tratar as situações de abuso sexual está relacionado a tabus presentes na sociedade em relação ao tema. Contribui para essa hipótese o alto índice de subnotificação de casos de abusos, sobretudo quando o agressor é o próprio pai ou outro membro da família. Diante da escassez de pesquisas aliadas ao despreparo profissional, Vitriol et al. (2007) alertam para o fato de que o sistema de saúde como um todo corre o risco de reproduzir o silêncio da sociedade e favorecer a revitimização.
Vítimas de abuso possuem uma demanda específica. Apesar de buscarem auxílio psicoterápico para lidarem com os sintomas decorrentes do trauma vivido, apresentam elevada resistência em abordar a situação abusiva, podendo demorar mais tempo para estabelecer um vínculo de confiança com o psicólogo. Numhauser e Soto (2006) destacam a importância da relação transferencial no tratamento dessa população. Essa pode assumir configurações positivas, que ajudam na elaboração do trauma, ou configurações negativas, que podem reproduzir uma situação de vitimização.

Nos casos estudados, observou-se que, mesmo em atendimentos breves, a situação do abuso pôde ser trabalhada, ocorrendo expressiva diminuição dos sintomas na grande maioria dos casos. Esse fato também foi observado por Vitriol et al. (2007). Os autores relatam que, mediante intervenções pautadas na metodologia baseada em evidência, que permitiu à equipe de saúde explorar ativamente os antecedentes traumáticos de mulheres vitimizadas, foi possível observar melhoras em curto espaço de tempo. Nesse sentido, pesquisas que aprofundem a compreensão sobre as modalidades de atendimento psicoterapêutico oferecido às vítimas de agressões sexuais e suas variáveis poderiam oferecer subsídios para uma atuação clínica mais eficiente.

Do ponto de vista preventivo, é importante destacar que grande parte dos abusadores ou pais negligentes foram vítimas de abuso na infância ou adolescência - transmissão transgeracional (Vitriol et al., 2007). Portanto, ao tratar as vítimas de abuso, diminui-se a probabilidade de que elas venham a perpetrar ou favorecer abusos contra seus filhos ou outras crianças. 


\section{Referências}

Paulo Afrânio Sant'Anna*

Universidade Presbiteriana Mackenzie

Doutor em Psicologia clínica - IPUSP

\section{Ana Paula da Silva Baima}

Universidade Presbiteriana Mackenzie

Especialista em Psicologia hospitalar - Faculdade de Medicina da USP

\section{*Endereço para envio de correspondência:}

Rua Henrique Botticini, 44

Butantã, São Paulo, Brasil CEP: 05587- 020

E-mail: pauloasantanna@pauloasantanna.psc.br
Aded, N. L. O., Dalcin, B. L. G. S., Moraes, T. M., \& Cavalcanti, M. T. (2006). Abus o sexual em crianças e adolescentes: revisão de 100 anos de literatura. Revista de Psiquiatria Clínica, 33(4), 204-213.

Alberto, I. M. M. (2002). Feios, porcos e maus: do erro fundamental à abordagem sistêmico-ecológica na avaliação das situações de abuso sexual. Psychologia: Revista da Faculdade de Psycologia e de Ciências da Educação de Coimbra, 9(30), 69-77.

Alberto, I. M. M. (2000). As consequêencias do abuso sexual infantil: contributo dos estudos longitudinais. Psychologia: Revista da Faculdade de Psycologia e de Ciências da Educação de Coimbra, 7(24), 119-127.

Amazarray, M. R., \& Koller, S. H. (1998). Alguns aspectos observados no desenvolvimento de crianças vítimas de abuso sexual. Psicologia: Reflexão e Crítica, 11(3), 559-578.

Azevedo, E. C. (2001). Atendimento psicanalítico a crianças e adolescentes vítimas de abuso sexual. Psicologia: Ciência e Profissão, 21(4), 66-77.

Azevedo, M. A., \& Guerra, V. N. A. (1989). Crianças vitimizadas: a síndrome do pequeno poder. São Paulo: Iglu.

Azevedo, M. A., \& Guerra, V. N. A. (1998). Pele de asno não é só história: um estudo sobre a vitimização sexual de crianças e adolescentes em família. São Paulo: Roca.

Cohen, C. (1993). O incesto, um desejo. São Paulo: Casa do Psicólogo.

Cohen, C., \& Gobetti, G. J. (2004). O incesto: o abuso sexual intrafamiliar. Recuperado em 15 de janeiro de 2004, de http:// www.violenciasexual.org.br

Echeburúa, E., \& Corral, P. (2006). Secuelas emocionales en víctimas de abuso sexual en la infancia. Cuadernos de Medicina Forense, (43-44), 75-82.

Ferreira, J. D. (2000). Estudo de fatores relacionados com a violência sexual contra crianças, adolescentes e mulheres adultas. Tese de Doutorado em Medicina, Centro de Referência da Saúde da Mulher e de Nutrição, Alimentação e Desenvolvimento Infantil, Universidade de São Paulo, São Paulo.

Finkelhor, D., \& Browne, A. (1986). The traumatic impact of child sexual abuse. American Journal of Orthopsychiatry, 530-541.

Furniss, T. (1993). Abuso sexual da criança - uma abordagem multidisciplinar. Porto Alegre: Artes Médicas.
Habigzang, L. F., Hatzenberger, R., Corte, F. D., Stroeher, F., \& Koller, S. (2008). Avaliação de um modelo de intervenção psicológica para meninas vítimas de abuso sexual. Psicologia: Teoria e Pesquisa, 24(1), 67-76.

Kendall-Tacket, K. A., Williams, L. M., \& Finkelhor, D. (1993). Impact of sexual abuse on children: A review and synthesis of recent empirical findings. Psychological Bolletin, 113(1), 164-180.

Maia, A. C. (2001). Abuso sexual na infância: a reconstrução depois do trauma. Psicologia: Teoria, Investigação e Prática, 6(2), 347-357.

Matias, D. P. (2006). Abuso sexual e sociometria: um estudo dos vínculos afetivos em famílias incestuosas. Psicologia em Estudo, 11(2), 295-304.

Meichenbaum, D. (1994). Victims of child sexual abuse: A clinical handbook/practical therapist manual of assessing and treating adults with post-traumatic stress disorder (PTSD). Ontário: Institute Press.

Neumann, M. M. (2002). Violência sexual: dominação e sexualidade. Dissertação de Mestrado em Psicologia Social, Pontifícia Universidade Católica de São Paulo, São Paulo.

Pfeiffer, L., \& Salvagni, E. P. (2005). Visão atual do abuso sexual na infância e adolescência. Jornal de Pediatria, 81(5), 197-204.

Numhauser, J., \& Soto, P. (2006). Consejos en la psicoterapia de mujeres víctimas de incesto: Revisión de 59 casos. Revista Chilena de Neuro-Psiquiatría, 44(4), 271-281.

Rivera-Rivera, L., Allen, B., Chávez-Ayala, R., Ávila-Burgos, L. (2006). Abuso físico y sexual durante la niñez y revictimización de las mujeres mexicanas durante la edad adulta. Salud Pública de México, 48(2), 268-278.

Stein, R. (1978). Incesto e amor humano: a traição da alma na psicoterapia. São Paulo: Símbolo.

Teicher, M. H. (2000). Feridas que não cicatrizam: a neurobiologia do abuso infantil. Cerebrum Belmont, 2(4), 50-67.

Universidade de Guadalajara. Centro de Intervencíon en Crisis. (1998). Los delitos sexuales: su prevención y manejo. In XX Jornada para la Salud Mental, Guadalajara.

Vitriol, V. G. (2005). Relación entre psicopatología adulta y antecedentes de trauma infantil. Revista Chilena de NeuroPsiquiatría, 43(2), 83-87.

Vitriol, V. G. \& Vasquez, M. Iturra, L. L., \& Muñoz, C. R. (2007). Diagnóstico y abordaje de secuelas por abuso sexual infantil en tres mujeres consultantes a un servicio de salud mental de hospital general. Revista Chilena de Neuro-Psiquiatría, 45(1), 20-28. 